\title{
Systems innovation tools
}

\author{
K. Cormican and D. O'Sullivan \\ Computer Integrated Manufacturing Research Unit (CIMRU) \\ National University of Ireland, Galway, Ireland. \\ Tel: +353.91 .705414$ \\ Fax: +353.91.562894; \\ e-mail:kathryn.cormican@nuigalway.ie
}

\begin{abstract}
Manufacturing organisations are continuously innovating their systems and processes in order to survive in today's turbulent environment. There are currently a number of software tools available on the market, which can help managers and decision makers innovate their systems. These tools range from sophisticated modelling and simulation tools to project management tools. Each tool has their own unique selling propositions, specialised capabilities and relative strengths and weaknesses. However, most are operated by a single user and require a considerable amount of expertise. This paper highlights features found in some of these tools and used in organisations to facilitate systems innovation. It examines a sample of tools that are currently available and finally, it introduces a new software solution called Systems Innovation Manager (SIM). SIM is based on a collaborative approach to planning, implementing and managing innovation in a systems environment. It is an integrated system consolidating strategy, people and project related issues.
\end{abstract}

\section{Keywords}

Modelling tools; Systems innovation management; Decision support system.

\section{INTRODUCTION}

The manufacturing environment is currently evolving; it is now characterised by globalisation, variety and time based competition (Browne et al, 1996; O'Sullivan, 1994). To win in such an environment organisations must deploy new and better products and services faster than their competitors. In order to develop such products and services companies must design and build the appropriate facilitating infrastructure. According to Daft (1992) traditional organisations divide work into 
functional areas and rely excessively on chains of command. However, boundaries and bureaucracies slow down the decision making process and impede and distort information by passing it from one person to the next. Simply put, traditional organisational structures do not support the new paradigms that are needed for competitiveness. Today's manufacturing organisations must be flexible, malleable and agile in order to meet the present challenges (Drucker, 1993; Nonaka, 1991). They need an architecture, which supports flexible and organic structures that enable innovation and responsiveness. Their process and systems should be open and capable of reaching across functions and hierarchies, and information should be able to flow freely to where it is useful. It is becoming increasingly evident that manufacturing organisations must redesign and change their processes and systems in order to become more flexible and responsive and to support the creative problem solving necessary to survive in today's environment.

\section{SOFTWARE TOOLS}

Many software tools have been developed to facilitate the identification of planned changes to the business prior to the implementation of such changes and to evaluate activities, complex processes and business component interdependencies. These tools are referred to in this article as systems innovation tools. Such tools seek to model, visualise, analyse and simulate the systems or process they are reengineering. Essentially, they support the user in systems innovation by building models representing an organisations existing processes (as is) or proposed processes (to be). These models can be simulated in order to analyse systems performance. Consequently, systems innovation tools can help the decision maker to;

- View the business from a holistic perspective

- Identify constraints and bottlenecks within the process

- Forecast the effects of planned changes

- Reduce interdepartmental complexities

- Increase efficiency and effectiveness

- Minimise costs.

\section{SOFTWARE CAPABILITIES}

Software tools are constantly evolving and at present the marketplace offers enhanced capabilities for users of both high and low end tools. There are many programmes available, ranging from sophisticated simulation and modelling packages to basic object flow-charting and activity modelling packages. While workflow software and simulation packages are part of a natural continuum, software solutions are currently falling into separate categories. The following evaluation identifies a set of features, which reflect the issues that concern the 
prospective user and therefore could be included in a comprehensive systems innovation tool-set. It also compares a sample of tools against these features. Such an evaluation presents a reasonable and accurate description of systems innovation tools in terms of user requirements and will allow prospective users to compare different tools against each other. The tools on the market may offer some, or a combination of, the following functions in various ways: modelling, simulation, project planning, organisational entity analysis and business metrics.

- A modelling capability within a software tool is used to build a model of a particular process and identify the activities and other attributes associated with that process or system.

- A simulation capability refers to the ability of a tool to simulate dynamic processes. In other words, this tool illustrates the proposed model (to-be model) and provides contingency or "what-if" analysis.

- Project planning helps the user map out the overall strategy for implementing a systems innovation programme throughout an organisation.

- Organisation entity analysis is used for illustrating the organisation's structure in terms of its functions and hierarchies. It should be able to highlight the specific changes that occur as a result of adding or removing an additional organisational entity.

- Finally, business metrics tools are used for monitoring such things as productivity, efficiency, effectiveness, quality, service delivery, and responsiveness.

If software tools are compared against these features it seems that many tools appear to offer some, or a combination of these features. The following list provides a sample of the software tools available. While this list is by no means exhaustive it does give an insight into the products available on the market and which span the spectrum of features required.

\section{REVIEW OF EXISTING TOOLS}

Business Design Facility (BDF) is developed by Texas Instruments Inc. and it is used to model and simulate particular business processes. It offers the facility to graphically represent an organisation's structure and processes which helps the user to gain knowledge on the performance of the process. BDF allows users to create a graphical model of a specific business process (as is model). This model may be redesigned to produce the desired "to-be" model. BDF also outlines the flow of information within the sub processes and matrices are used to compare and contrast process features. BDF uses the Dynamic Data Exchange (DDE) facility to export data to external software systems in order to simulate models. This allows the user to assess the performance of the process under a set of given conditions. The user can then make changes to the process and assess the affect of these changes. BDF is targeted at the high end of the market, it is expensive and requires 
much practice to master. Furthermore, the graphical user interface is not very sophisticated or user friendly.

FirstSTEP is created and developed by Interfacing Technologies. This tool allows the user to build a profile of an organisation or system. The processes and sub-processes in each of the functions or departments shown in the organisational profile can then be modelled. The user can identify who is responsible for undertaking specific actions by using icons on the graphical model. The organisation's process can be simulated and changed and the effects of the changes are then analysed and assessed. FirstSTEP is also aimed at the high end of the market. It is expensive, restrictive and requires many iterations to get it right. A large amount of detail is required to build a simple process model and the data entry process is confusing, as the same information must be entered in different windows.

IDEF0 was developed by the US Airforce and is a method used to establish the scope of an analysis by modelling the activities and actions of an organisation or system. IDEF0 models are designed to enhance communication by using diagrams based on simple box and arrow graphics and hence, they are often created as one of the first tasks of a systems innovation initiative. Activities are described in terms of their inputs, outputs, controls and mechanisms. This helps the user to identify what activities are performed in an organisation, and what is needed to perform those activities. It also helps the user to assess the performance of the current system or process. IDEF0 models are so concise that they are only understandable if the reader is an expert or has participated in developing the model. While it is not intended for modelling activity sequences, there is a tendency to interpret the diagrams as portraying a sequence of activities.

As the re-engineering discipline moves further down into organisations, less sophisticated, user friendly software is needed to integrate systems innovation with other key pieces of information. Software such as Workflow tools is targeted at the lower end of the market. For example, Micrographix FlowCharter allows the user to draw process flowcharts, data flow diagrams, network diagrams and organisation charts. It can create interactive diagrams of business processes and workflows and transform static diagrams into dynamic, interactive processes. This software also integrates with the Microsoft desktop. While these tools do not offer sophisticated simulation capabilities they allow the user to model systems and processes. These tools are inexpensive, flexible and easy to use.

Microsoft Project is targeted at Project Managers in order to co-ordinate activities within the project planning phase of a systems innovation initiative. It helps the user to organise major projects into manageable groups of tasks by using Gantt charts, PERT charts and resource allocation techniques. Microsoft Project helps the user to identify the main tasks to be accomplished within a specified time frame and the relevant people and skills required to execute these tasks. It also allows project managers to refine schedules and monitor progress periodically. However, in order to maximise the potential of this tool all data entered must be accurate and updated regularly. 
Microsoft's Team Manager is used to manage entire suites of projects and the teams assigned to implementing them. It helps the user to co-ordinate team activities effectively by organising and prioritising tasks, activities and deadlines. Team Manager can use an organisation's existing e-mail system or network to disseminate new or updated information and regular status reports between team members so everyone has access to complete, accurate and timely information. Team Manager allows the user to adjust deadlines, verify that work estimates are reasonable and team members aren't overlooked. It also allows the user to evaluate progress accurately and effectively by monitoring a team's performance relative to its goals.

Analysts and software vendors can argue endlessly about the relative strengths and weaknesses of various systems innovation software tools. Each of them offers various modelling, simulation and project management capabilities to their users. However, there is no single product available that can deliver all the features users now want. In general, the systems innovation tool industry lacks integration. Furthermore, none of these tools offer intelligent decision support or systems innovation expertise to the users. All this expertise must be brought to the tool by the user. It seems that there is a need for software tools, which have strong graphical user interfaces, easier to operate and configure and incorporate either a decision support system or an expert system.

\section{SYSTEMS INNOVATION MANAGER}

Systems Innovation Manager (SIM) is a software tool to facilitate systems innovation. It is targeted at organisations wishing to undertake numerous systems innovations projects simultaneously throughout the organisation. The tool has been developed to incorporate modelling, project planning, organisational entity analysis and business metrics. The goal is to identify, integrate and co-ordinate the most valuable and successful ways to change an organisation. Systems Innovation Manager encourages all employees in the organisation to identify problems and suggest ideas. Ideas are organised and prioritised taking the specific organisational strategy into consideration. Some go to continuous improvement while others are transformed into projects where resources are allocated and people assigned responsibility. This tool offers an impressive decision making capability as all workers can access and manipulate the data. Systems Innovation Manager can be visualised through the development funnel as highlighted in Figure 1 below. 


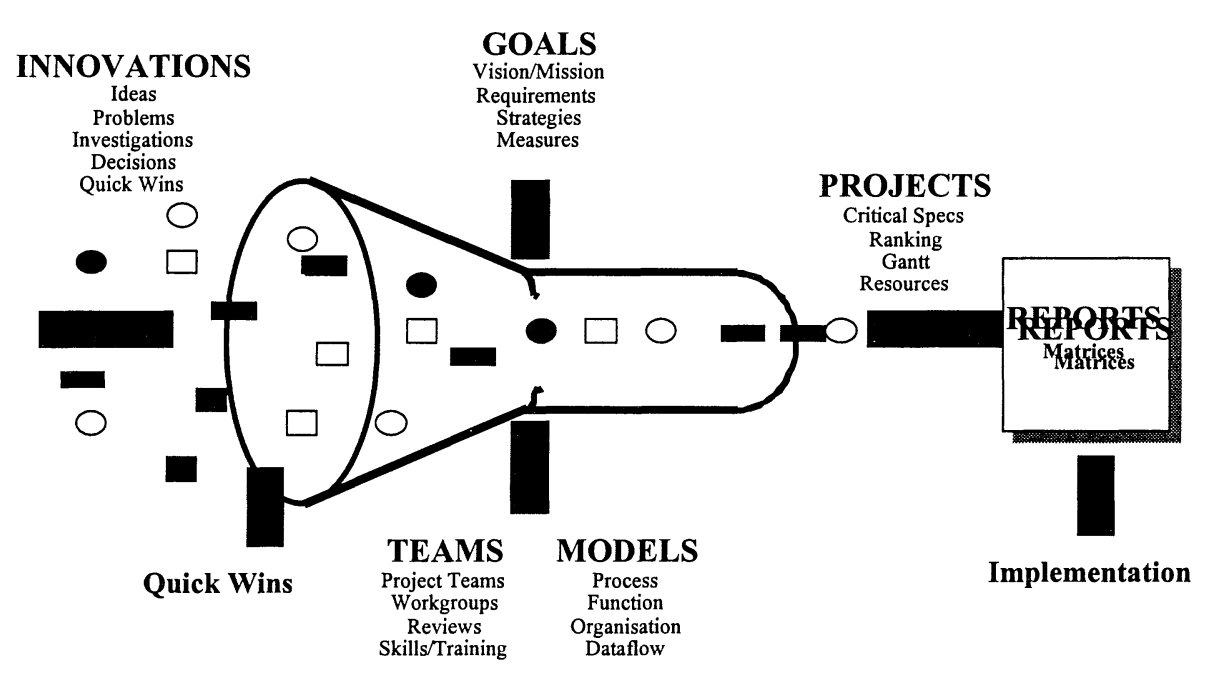

Figure 1: Systems Innovation Manager

The mouth of the funnel is fed continuously by ideas for innovation that may improve an organisation's performance. Some of these ideas can result in small continuous improvements (or quick wins), while others can lead to large projects that result in a radical change in performance. These ideas are generated by all employees and inputted through their terminals. They may represent both small incremental improvements and ideas for large-scale innovations. Ideas that lead to continuous improvements and do not require major resources need not flow fully into the funnel and can be implemented immediately by the individuals or groups concerned. Ideas or projects which do require major resources flow into the funnel until they become constrained by a number of important factors - the operations strategy, performance goals, available budgets and available personnel required to implement the proposed change. They can also be constrained by the agreed architecture or model developed for the system. Projects, which are aligned with the organisation's strategy and goals, are considered appropriate and can proceed through the funnel. These are referred to as approved projects, and eventually find their way onto the organisation's 'systems innovation plan'. The projects on the plan eventually go through a new process of specification by the individual project groups involved, budget approval by senior management and eventual implementation.

The main objective of systems innovation manager is to maximise the effort and resources that are expended on performance improvement. Empowering employees and involving all personnel in problem solving secures ownership and increases the resources available to generate, exploit and implement ideas (Martin, 1995; Davenport and Prusak, 1998). Developing a consensus-based strategy among managers focuses ideas towards goal-centred projects. In addition, strategically important projects can be structured into a systems innovation plan that acts as a 
blueprint for implementing effective change. SIM provides seamless information about all workforce options. It consolidates all strategy, people and project related issues in the manufacturing enterprise. By providing one source for this information any manager can easily perform consolidated searches. With one integrated system, all information for reach individual is automatically updated and is easily accessible. As well as coordinating and communicating the programmes that are available to the workforce, such a system can also offer continuous learning opportunities. SIM can support multiple users across the enterprise. It delivers productivity enhancing, collaborative workflow and self-service capabilities using advanced technologies such as the GroupWare and Intranets. Self-service technologies not only extend the SIM capabilities to the workforce, but also add additional value by promoting a more collaborative work environment. With the new workforce paradigm focusing on teams and projects, the new system must support and bring efficiencies to these work group models.

\section{CONCLUSION}

As we approach the $21^{\text {st }}$ century it is increasingly apparent that the survivors in this new era of manufacturing will be those organisations that are rigorous in their pursuit of innovation. Manufacturing organisations need to innovate their systems in order to develop new ways of producing goods, services and information. It is also increasingly clear that the only way to achieve this goal is to energise, empower and enable all employees to participate in the decision making process. Therefore manufacturing organisations must provide the appropriate support systems and infrastructures to facilitate this. It is believed that an integrated tool set based on a sound methodology associated with some effective processes will facilitate the systems innovation (Lyons, 1997). Systems Innovation Manager (SIM) is a software tool which, not only allows an organisation to encapsulate an ever growing body of human know how, but also increases corporate transparency. This could become a valuable strategic resource that could not be replicated quickly by competing companies. Therefore, this tool could make a competitive difference. However, it is important to remember that tools and technologies are not the answer to innovation. They can certainly facilitate the implementation of the innovation process - the generation, transfer and implementation of innovation - and in some cases they may be able to automate some kinds of work. Systems Innovation Manager is a means to an end and not an end in itself. In other words, it must be taken in context and implemented as part of an overall effort to leverage organisational innovation. It will have to be adapted to the way people work, taking into consideration their organisation's culture and value systems. 


\section{REFERENCES}

Browne, J., Harhen, J. and Shivnan, J. (1996). Production Management Systems:

An Integrated Perspective. Second Edition. Harlow: Addison-Wesley.

O’Sullivan D. (1994). Manufacturing Systems Redesign, London: Prentice Hall.

Davenport, T.H. and Prusak, L. (1998). Working Knowledge: How Organisations Manage What They Know, Boston: Harvard Business School Press.

Drucker, P. (1993). Post Capitalist Society, New York: Harper Business.

Daft, R.L. (1992). Organisational Theory and Design, $4^{\text {th }}$ Edition, St. Paul: West Publishing Company.

Lyons, G. (1997). The Role of Information Technology in Enterprise Engineering, Knowledege and Process Management, 4, 1, pp 268-277.

Nonaka I. (1991). The Knowledge Creating Company, Harvard Business Review, Nov-Dec pp 96-104.

Martin J. (1995). The Great Transition, USA: AMACOM Publishing.

\section{BIBLIOGRAPHY}

Kathryn Cormican is a research engineer with CIMRU at the National University of Ireland, Galway. She is currently undertaking research towards a Ph.D. in the area of enterprise modelling. Kathryn holds a BBS and an MBS in process redesign. Prior to joining CIMRU, she worked as a consultant specialising in strategic and operational change.

David O'Sullivan (Ph.D.) is a lecturer and research director at the National University of Ireland, Galway. His research interests are in the areas of manufacturing systems design and change management where he directs a number of research projects. David has many successful publications including books on Manufacturing Systems Redesign (Prentice-Hall), Reengineering the Enterprise (Chapman \& Hall) and the Handbook of IS Management (Auerbach). In 1995 David was honoured with the prestigious 'Outstanding Young Manufacturing Engineer of the Year' award by the Society of Manufacturing Engineers, Dearborn, Michigan. 